\title{
Caracterização de quartzo para obtenção de suas variedades gemológicas por irradiação gama elou tratamento térmico
}

\author{
Quartz characterization to obtain its gemological varieties by \\ means of gamma irradiation and/or heat treatment
}

Ney Friedemann Drummond

Especialista em Gemologia Mestrando em Gemologia do DEGEO/EM/UFOP

E-mail:neydrummond@degeo.ufop.br

Júlio César Mendes

Engenheiro Geológico Doutor em Geociências e Professor do DEGEO/EM/UFOP E-mail: julio@degeo.ufop.br

\section{Fernando Soares Lameiras \\ Físico, Pesquisador Titular Professor - CDTN/BH E-mail:fsl@cdtn.br}

\section{Resumo}

Apesar da grande produção de quartzo em Minas Gerais, pouco é conhecido sobre a influência do ambiente geológico na geração das variedades coloridas através de tratamento. Sabe-se que a irradiação gama, seguida ou não de aquecimento, conduz à formação de cores, tais como acontece com a ametista, prasiolita, green gold, beer, cognac, whisky e champagne. Amostras de ambientes hidrotermal e pegmatítico foram submetidas a ensaios por espectroscopia de absorção na região do infravermelho por transformada de Fourier (FTIR) e irradiação gama seguida ou não de tratamento térmico. Os espectros obtidos por FTIR mostram bandas correlacionadas a elementos dopantes, os quais indicam o potencial da amostra pelo aparecimento de cor e permitem determinar as doses que serão aplicadas na irradiação gama e as temperaturas que serão utilizadas no tratamento térmico. Os resultados dos ensaios mostraram que quartzo de ambiente hidrotermal com valores anômalos de ferro, com banda FTIR a $3.585 \mathrm{~cm}^{-1}$, fator $f a \geq 3,3$ e área entre 400 e $600 \mathrm{u} . \mathrm{a}^{*} \mathrm{~cm}^{-1}$, poderá desenvolver a cor violeta; quartzo com anomalias de lítio na estrutura do cristal derivado de núcleo de pegmatitos altamente diferenciados ricos em minerais de lítio apresentando banda FTIR a $3.485 \mathrm{~cm}^{-1}$, fator $f L i \geq 2,0$ e irradiado com doses de 65 a 400kGy pode desenvolver cores amarelo-esverdeadas a acastanhadas. É possível concluir que ametista e prasiolita são produzidas de quartzo de ambiente hidrotermal, enquanto variedades gemológicas raras, tais como green gold, beer, cognac, whisky e champagne são produzidas de quartzo de pegmatitos altamente diferenciados, que contêm minerais de lítio.

Palavras-chave: Quartzo, irradiação gama, tratamento térmico, espectro FTIR, gemologia, Minas Gerais.

\begin{abstract}
Despite the large production of quartz in Minas Gerais, little is known about the geological environment influence on the generation of colored varieties by treatment. It is known that gamma irradiation, followed or not by heating, leads to the generation of colors such as amethyst, prasiolite, green gold, beer, cognac, whisky and champagne. Samples from hydrothermal and pegmatitic environments were subjected to tests by absorption spectrometry in the infrared region with the FOURIER transform (FTIR), gamma irradiation and heat treatment. The obtained
\end{abstract}


FTIR-spectra show characteristic bands correlated to doping-elements, which indicates the color appearance potential of the sample, and allow to quantify the applied doses of gamma irradiation and the temperatures in heat treatment. The results of the tests indicate that quartz from a hydrothermal environment with anomalous levels of iron, with FTIR-band of $3585 \mathrm{~cm}^{-1}$, factor fa $\geq 3.3$ and area between 400 a 600 u. $\mathrm{a}^{*} \mathrm{~cm}^{-1}$, may develop a violet color; quartz with lithium anomaly in the crystal structure derived from nuclei of highly differentiated pegmatites rich in lithium minerals, presenting FTIR-band of $3485 \mathrm{~cm}^{-1}$, fLi factor $\geq 2$ and irradiated with doses of 65 to $400 \mathrm{kGy}$, may develop yellow-green and brown colors. It is possible to conclude that amethyst and prasiolite are produced from quartz from a hydrothermal environment, while rare varieties such as green gold, beer, cognac, whisky and champagne are generated from quartz from highly differentiated pegmatites that bear Liminerals.

Keywords: Quartz, gamma irradiation, heat treatment, FTIR-spectra, gemology, Minas Gerais.

\section{Introdução}

Desde o século passado, são conhecidos, em Minas Gerais, os depósitos de quartzo hialino de veios hidrotermais encaixados em quartzitos da serra do Espinhaço (Moraes, 1937) e os de núcleos de pegmatitos da Província Pegmatítica Oriental (Paiva, 1946). No Brasil, a partir de 1997, descobriu-se que desse quartzo se pode obter variedades coradas de gemas, quando submetido a doses de irradiação gama variando de 65 a 1.000kGy de uma fonte de Co-60, seguidas, ou não de tratamento térmico (Lameiras, 2007). O cristal pode permanecer incolor, aparecer matizes já conhecidos como o da ametista, citrino, prasiolita e morion ou fumê ou mesmo novas cores denominadas de green gold, beer, cognac, whisky e champagne.
Portanto esse trabalho visa a definir quartzo de quais jazidas podem apresentar potencial de mudança de cor, o ambiente geológico no qual elas estão inseridas, as características químicas do cristal, as técnicas analíticas aplicadas nesse processo e os minerais-gemas resultantes do tratamento desse quartzo hialino.

\section{Materiais e métodos}

Aproximadamente $10 \mathrm{~kg}$ de quartzo hialino foram coletados em cada uma das minas de ambientes hidrotermal e pegmatítico. No hidrotermal, foram selecionadas as Minas do Tião e Comecha. Na Mina do Tião, situada no topo da serra do Espinhaço em Buenópolis (Minas Gerais), com latitude $17^{\circ} 47^{\prime} 01^{\prime \prime}$ 'S e longitude $43^{\circ} 52^{\prime} 22^{\prime \prime} \mathrm{W}$, foram selecionados 60 espécimes com peso variável, entre 6 e 20g; enquanto na Comecha, situada no platô da serra do Cabral em Francisco Dumont (Minas Gerais), com latitude $17^{\circ} 39^{\prime} 35^{\prime}$ 'S e longitude $44^{\circ} 14^{\prime} 26^{\prime \prime} \mathrm{W}$, foram selecionadas 40 amostras, com peso entre 10 e $60 \mathrm{~g}$. No ambiente pegmatítico, os trabalhos de campo foram feitos nas Minas Boca Rica e do Bode. Da Mina Boca Rica (18 50 '37's e

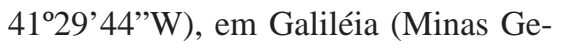
rais), foram escolhidos 25 espécimes de quartzo de núcleo pegmatítico, com peso entre 10 e $110 \mathrm{~g}$; da Mina do Bode (1905'02”'S e 4130'33”'W), situada no município de Conselheiro Pena (Minas Gerais) foram separadas 40 amostras pesando entre 6 e 102g. Na Figura 1, é mostrada a localização dessas minas de quartzo hialino nos ambientes hidrotermal (Minas do Tião e Comecha) e pegmatítico (Minas Boca Rica e do Bode).

As amostras selecionadas de quartzo foram submetidas à espectrografia de absorção na região do infravermelho com Transformada de FOURIER (FTIR). Essa técnica permite definir em quais cristais é possível o aparecimento de novos matizes de cores. Caso apareçam novas cores, significa que o quartzo porta elementos dopantes (Al, $\mathrm{Fe}, \mathrm{Li}$, Na e H), os quais precisam de ser medidos. Antes das análises químicas, os ensaios de irradiação gama (com doses variáveis) seguidos ou não de tratamento térmico, podem confirmar os resultados de infravermelho. A etapa seguinte consistiu na obtenção de resultados analíticos por via úmida $\left(\mathrm{SiO}_{2}\right)$ e por espectrometria de emissão atômica, por plasma de acoplamento induzido (ICP/AES) para os elementos traços, principalmente os possíveis causadores de cores.

Os ensaios de FTIR foram feitos no Laboratório de Espectrometria na Região do Infravermelho e Ultravioleta e Visível (LABESPEC) do Centro de Desenvolvimento da Tecnologia Nuclear (CDTN/BH), utilizando um aparelho Bomem, modelo MB, e outro Perkin Elmer, modelo Spectrum 100. Esses ensaios foram realizados em temperatura ambiente, com resolução de $4 \mathrm{~cm}^{-1}$ e número de varreduras de 16 a 128, com o objetivo de reduzir as incertezas provocadas por ruídos, e numa região de comprimento de onda entre 3.018 e $3.630 \mathrm{~cm}^{-1}$. As amostras utilizadas, nesses ensaios, tinham espessura de 1 a $3 \mathrm{~mm}$.

Os ensaios de irradiação gama, utilizando radionuclídeo Co-60, foram realizados no Laboratório de Irradiação Gama (LIG) da CDTN/BH. Nessa etapa, as amostras são colocadas em sacos plásticos, onde são escritas as doses em kGy (65, 200, 300, 400 e 600) a que devem ser submetidas e o tempo de execução sendo determinado pelo técnico responsável.

O tratamento térmico foi feito nos laboratórios da CDTN/BH, utilizando-se de uma mufla, com a mudança de cor sendo observada numa janela de vidro na sua porta. A temperatura foi atingida com aquecimento lento e gradual, para evitar o aparecimento de fratura no cristal. A temperatura e o tempo foram indicados pelos ensaios de FTIR e de irradiação gama, podendo variar de 280 a $325^{\circ} \mathrm{C}$ e entre 5 e 60 minutos.

Para a determinação dos elementos maiores e traços, foram feitas análises químicas por via úmida e ICP/AES. Uma amostra de quartzo de cada mina foi selecionada para as análises por via úmida feitas no Laboratório de Geoquímica 
Ney Friedemann Drummond et al.

(LabGeo) do Departamento de Geologia da Escola de Minas da Universidade Federal de Ouro Preto (DEGEO/EM/ UFOP), para a determinação da percentagem de $\mathrm{SiO}_{2}$. Os ensaios de ICP/AES foram feitos no LabGeo, num aparelho SPECTRO, modelo CIROS(CCD), dosando 27 elementos químicos, com limites de detecção na faixa de décimos de ppm.

Num mesmo corpo e em um mesmo ambiente geológico, o teor de impurezas pode variar e o espectro de FTIR indica o potencial de desenvolvimento de cor e/ou matiz resultante no quartzo. A região mais utilizada para a avaliação do FTIR situa-se entre 3.018 e $3.630 \mathrm{~cm}^{-1}$, onde podem ser encontradas 12 bandas associadas às impurezas causadoras de cor (Lameiras, 2007). Os espectros de FTIR foram normalizados de tal forma a obter a absorção em $2.685 \mathrm{~cm}^{-1}$ igual a 1 , uma vez que essa banda, presente em todas as amostras de quartzo, não se relaciona à formação da cor (Nunes et al., 2009). A linha de base é definida na faixa entre 4.100 e $5.300 \mathrm{~cm}^{-1}$ e subtraída do espectro normalizado, em função de não se observarem bandas de absorção (parâmetro c). Essa linha de base está associada à orientação do cristal, ao teor de impurezas e às microinclusões. Calcula-se, também, a área sob a curva do espectro normalizado, entre 3.018 e $3.610 \mathrm{~cm}^{-1}$, a qual está relacionada com o teor de impurezas na amostra (Lameiras, 2007). Os parâmetros fa e fLi são calculados conforme Lameiras et al. (2006) e Nunes (2008) pela relação de altura entre bandas e a área no espectro na região do infravermelho. Nos espectros de quartzo hidrotermal, a área e o fator ametista ( $f a$ ) são indícios da intensidade de cor a ser obtida na irradiação e/ou aquecimento (Nunes, 2008). Um quartzo com banda em $3.585 \mathrm{~cm}^{-1}$, com fator $\mathrm{fa} \geq 3,3$ e área entre 400 e 600 u.a. ${ }^{*} \mathrm{~cm}^{-1}$ possui potencial para cor violeta da ametista; se fa estiver situado entre 2,7 e 3,3, não haverá o aparecimento de cor e, no caso de $f a \leq 2,7$ e área $\geq 1.500$ u.a.* cm $^{-1}$, irá aparecer o matiz esverdeado da prasiolita (Lameiras 2007). No quartzo pegmatítico, o fator lítio ( $f \mathrm{Li}$ ) é o indicador do potencial de geração de cor. Com o fator $f L i \geq 2,0$, quando irradiado a $150 \mathrm{kGy}$, aparece o verde-limão do green gold e, acima de $300 \mathrm{kGy}$, aparece a coloração acastanhada. Nos cristais com $f \mathrm{Li} \geq 2,0$, com área entre 50 e 180u.a. ${ }^{*} \mathrm{~cm}-1$, maior será o potencial de aparecimento de cor (Lameiras et al., 2006; Lameiras, 2007; Nunes, 2008).

Nas análises por via úmida e ICP/ AES, são medidos os diferentes causadores de cor em quartzo hialino de ambientes geológicos diversos. A aplicação da irradiação gama visa a acelerar

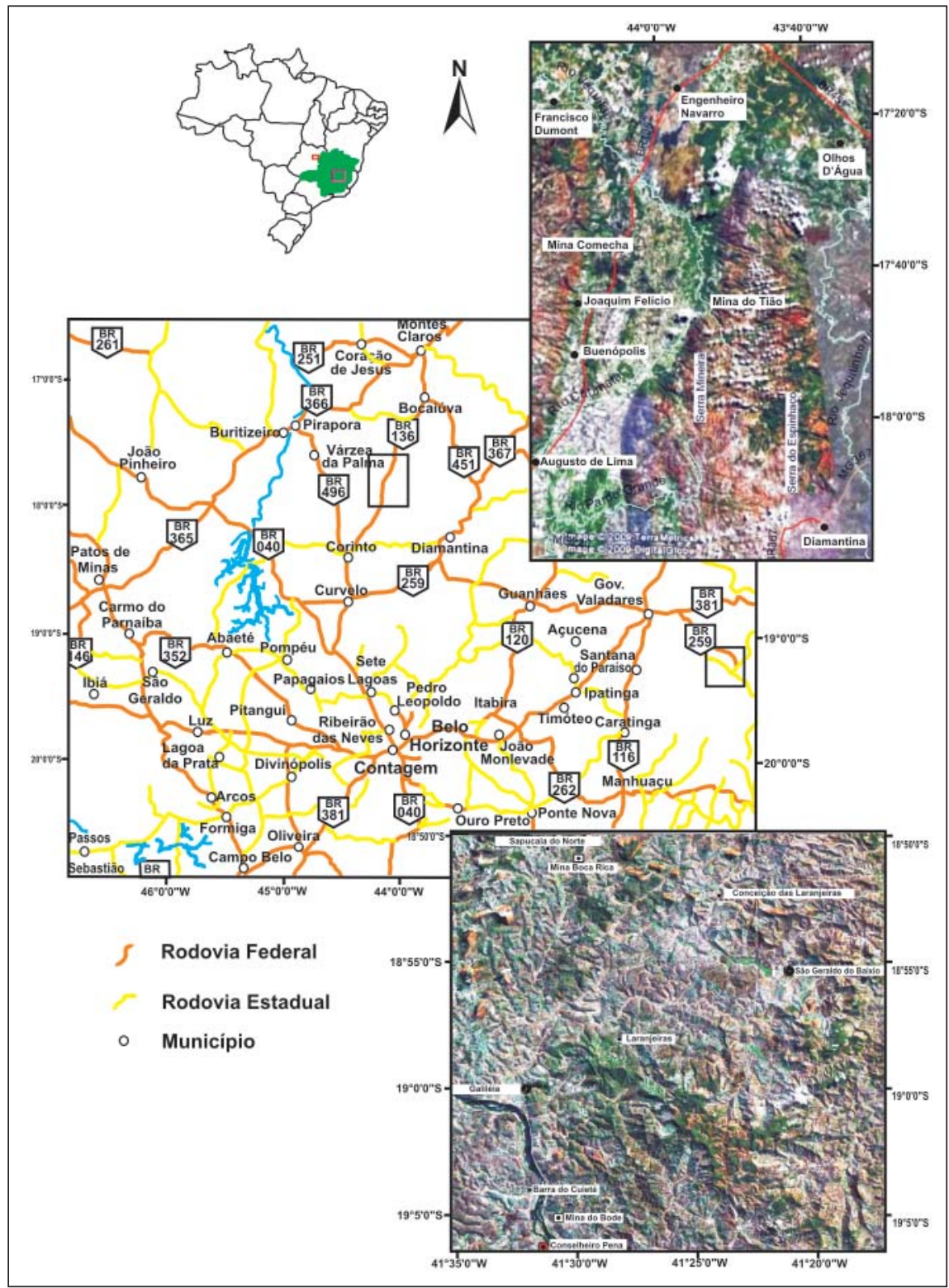

Figura 1 - Localização das minas de quartzo hialino nos ambientes hidrotermal (Minas do Tião e Comecha) e pegmatítico (Minas Boca Rica e do Bode) (imagens obtidas do Google Earth e do Google Maps). o aparecimento de cor devido à expulsão de elétrons no retículo cristalino, em função de defeito causado por íon dopante, e cria centro de cor no mineral. O centro causa instabilidade e quando irradiado (e/ou aquecido) permite o aparecimento de cor. No caso do quartzo, a irradiação, seguida ou não de tratamento térmico, cria cores já existentes na natureza (ametista, prasiolita, citrino e morion ou fumê) e novas variedades gemológicas (green gold, beer, cognac, whisky e champagne). Para Nassau (1994), 
a aplicação da irradiação não deixa resíduos radioativos e apresenta, como aspecto positivo, a produção de gema com coloração uniforme.

\section{O quartzo hialino e seus aspectos genéticos}

A variedade transparente e incolor de quartzo é denominada de cristal de rocha ou quartzo hialino. Aquela com característica de mineral-gema, portando dopante para irradiação, é encontrada em ambiente hidrotermal e pegmatítico. Em Minas Gerais, os veios hidrotermais com quartzo hialino são encontrados encaixados em quartzitos no segmento oeste do Espinhaço Meridional, na região de Buenópolis e Francisco Dumont. Carvalho (1982) menciona que esses veios estão relacionados a fluidos aquecidos e saturados em sílica, recristalizados ao longo de fratura e/ou falha. Nessa região, nas serras do Cabral e Mineira (uma denominação local para o Espinhaço Oeste), são encontrados espessos veios de quartzo hidrotermal com cristal hialino. Na serra do Cabral é encontrada a Mina Comecha, com veio de quartzo hialino com potencial gemológico; enquanto, na do Tião, o quartzo é hialino e mostra matiz violeta-pálido (ametista fraca). Quanto ao ambiente pegmatítico, o quartzo hialino é retirado do núcleo de pegmatito simples e diferenciado. Cristal hialino, com potencial para irradiação, somente é encontrado em pegmatito zonado e altamente diferenciado. O zonamento pegmatítico é muito bem definido nos pegmatitos diferenciados, sendo constituído pelas zonas de cristalização marginal, mural e intermediária em torno do núcleo quartzoso (Johnston Jr., 1945 a, b, Cameron et al., 1949). O núcleo quartzoso de pegmatito ígneo contém elementos responsáveis pela mudança de cor e, de suas porções hialinas, são obtidas as variedades gemológicas green gold, beer, cognac, whisky e champagne. O quartzo de núcleo pegmatítico de origem anatética não tem interesse gemológico, uma vez que os elementos dopantes não apresentam concentração suficiente para a mudança de cor. Nesse ambiente, não aparece núcleo bem definido, pois sempre existe a cristalização de outros minerais (feldspato e mica) junto com o quartzo. Para que o quartzo apresente potencial gemológico, deve ser hialino e possuir tamanho adequado e essas características só acontecem em pegmatito de sistema ígneo. Outro fator importante é a riqueza de voláteis, o que permite a incorporação de dopante, como o lítio, no quartzo. Os núcleos quartzosos com porções hialinas, passíveis de sofrerem mudança de cor no processo de irradiação, estão inseridos em corpos pegmatíticos portadores de elementos raros. O lítio desempenha um papel importante na mudança de cor e só naqueles pegmatitos onde ocorrem minerais de lítio o quartzo tem potencial para adquirir as colorações das variedades green gold, beer, cognac, whisky e champagne. A região entre Galiléia e Conselheiro Pena é clássica pela ocorrência de pegmatito altamente diferenciado e portador de elementos raros. Em função disso, nela foram amostrados cristais hialinos das Minas Boca Rica e do Bode.

\section{Resultados e discussões}

As análises de amostras de quartzo por ICP/AES (elementos traços) e por via úmida $\left(\mathrm{SiO}_{2}\right)$ visaram a definir as características do quartzo de ambientes hidrotermal e pegmatítico. Dos 27 elementos dosados por ICP/AES, Al, Fe e Li podem ser os responsáveis pela mudança de cor nas etapas de tratamento no quartzo (Lameiras, 2007). No ambiente pegmatítico, o alumínio no quartzo alcança valores até cinco vezes maiores do que no hidrotermal; existe uma similaridade no teor de ferro dos dois ambientes e o lítio, similar ao alumínio, é muito mais elevado no ambiente pegmatítico do que no hidrotermal (Drummond, 2009).

No quartzo de ambiente hidrotermal, os valores de alumínio estão entre 12 e 98,9ppm, na Mina do Tião, e entre 34,2 e 62,3ppm, na Mina Comecha; enquanto naquele de ambiente pegmatítico, os valores ficam entre 267,3 e 300,6ppm, na Boca Rica, e de 274,9 a 370,3ppm, na Mina do Bode. Quanto aos valores de ferro, eles estão compreendidos entre 104,4 e 253,4ppm, na Mina do Tião, e 131,8 e 180,0ppm, na Comecha, e de 80,7 a 165,0ppm, na Mina Boca Rica, e de 89,9 a 192,3ppm, na do Bode. O lítio no ambiente hidrotermal varia de 0,6 a $8,9 p p m$ e de 1,0 a 6,4, respectivamente, nas Minas do Tião e Comecha. No pegmatítico, de 60,2 a 66,3ppm, na Mina Boca Rica, e de 59,3 a 76,1ppm, na do Bode.

O matiz fumê, no quartzo, após irradiação, depende do teor de alumínio e da dose de irradiação (Lameiras, 2007). O ferro é considerado o responsável pela cor na ametista natural de origem hidrotermal, mas amostra com anomalia desse elemento (como as da Mina Comecha), quando irradiada, não apresenta cor comercial. Tal fato pode indicar que somente a presença do ferro, no quartzo de ambiente hidrotermal, não é responsável por ametista gemológica de cor intensa. Pode existir uma associação entre ambiente formador do quartzo e outro elemento químico, que, junto ao ferro, seja o responsável pelo matiz violeta-intenso. Collyer e Martires (1986), Chaves e Coutinho (1992), Cassini (1998) e Favacho-Silva (2000) verificaram a intima relação entre a presença de fonte termal ou a desintegração do $\mathrm{K}^{40}$ de argila rica em potássio e o matiz violeta da ametista, em várias regiões do Brasil, inclusive no Espinhaço (Favacho-Silva, 2000).

Os teores de $\mathrm{SiO}_{2}$ refletem a pureza do quartzo, mas não influenciam na mudança de cor no tratamento por irradiação e aquecimento. No ambiente hidrotermal, o teor de $\mathrm{SiO}_{2}$ foi 99,94\%, na Mina Comecha, e de 99,51\%, na do Tião. Teoricamente, o quartzo da Mina do Tião pode portar mais íons dopantes e maior probabilidade de mudança de cor, fato esse comprovado nesse trabalho. No entanto, não explica a ausência de cor nos cristais hialinos da Mina Comecha, mesmo após o tratamento, já que esses também possuem valores relativamente elevados de ferro. No ambiente pegmatítico, o teor de $\mathrm{SiO}_{2}$ é 99,98\%, na Mina Boca Rica, e de 99,12\%, no Bode. Esses percentuais não influenciam nos matizes criados na irradiação e no aquecimento e na entrada de dopantes, exceto no percentual de lítio (Drummond, 2009). 
As amostras da Mina do Tião mostram banda de FTIR a $3.585 \mathrm{~cm}^{-1}$ (Figura 2), um indicativo da criação de cor violeta. Para aplicação da dose de irradiação, foi considerado o fator ametista ( $f a$ ), associado ao formato do espectro na região entre 3.018 e $3.610 \mathrm{~cm}^{-1}$ (Nunes, 2008). As doses aplicadas foram 200, 400 e 600kGy.

As amostras da Comecha mostram bandas de FTIR em 3.380, 3.404, 3.434, 3.485 e $3.510 \mathrm{~cm}^{-1}$ (Figura 3), indicando a possibilidade de criação do matiz acastanhado, quando irradiado a 300kGy (Lameiras, 2007). Após irradiação gama, se confirmou o aparecimento da cor acastanhada. Alguns cristais, quando submetidos a tratamento térmico, retornam a incolor ou amarelo levemente pálido.

As bandas de FTIR a 3.400 e $3.510 \mathrm{~cm}^{-1}$ sempre ocorrem associadas e podem ser devidas à presença do ferro compensado por hidrogênio na estrutura do quartzo (Lameiras, 2007). A de $3.380 \mathrm{~cm}^{-1}$ está presente em qualquer quartzo e não é considerada no desenvolvimento de nova cor, enquanto aquela a $3.485 \mathrm{~cm}^{-1}$ fornece indício do matiz amarelo-esverdeado, devido ao alumínio compensado pelo lítio. Para a banda a $3.434 \mathrm{~cm}^{-1}$, é admitida uma associação do alumínio compensado pelo hidrogênio ou sódio (Lameiras, 2007).

Quanto ao quartzo de ambiente pegmatítico, as amostras da Mina Boca Rica mostram espectros de FTIR muito semelhantes (Figura 4). Para um comprimento de onda entre 2.300 e $3.500 \mathrm{~cm}^{-1}$, existem quatro bandas intensas. Uma primeira, a $3.595 \mathrm{~cm}^{-1}$, está possivelmente associada ao ferro compensado pelo lítio; a outra, a $3.484 \mathrm{~cm}^{-1}$, sobressaindo-se entre as demais e de intensidade muito forte, é atribuída ao alumínio compensado pelo lítio e é responsável pelo desenvolvimento da cor amarelada a acastanhada; uma terceira, entre 3.433 e $3.450 \mathrm{~cm}^{-1}$, é relacionada à presença de alumínio compensado pelo sódio e uma última, a $3.380 \mathrm{~cm}^{-1}$, presente em todo quartzo natural, ocorre devido a ligação de hidrogênio com uma ligação longa $\mathrm{Al}_{\mathrm{Si}}$ - O (Lameiras, 2007).

Os espécimes da Mina do Bode (Figura 5) mostram espectros similares aos da Boca Rica, podendo ser identificadas as mesmas quatro bandas, inclusive aquela a $3.484 \mathrm{~cm}^{-1}$, indicativa para o aparecimento do matiz amarelado e acastanhado.

Nessas duas minas de ambiente pegmatítico, se $f L i \geq 2,0$ e a dose de irradiação for inferior a $150 \mathrm{kGy}$, será criado o matiz amarelo-esverdeado (típico do green gold) e, para doses de irradiação de 300kGy, haverá o aparecimento do matiz acastanhado (típico do whisky) e matiz de conhaque (cognac), com valor comercial (Lameiras, 2007). O fator fLi é sempre maior nos cristais em que a banda é mais intensa, podendo atingir valores de até 3,5 e, sempre, está relacionado à intensidade de cor após irradiação e aquecimento.

As amostras das Minas Boca Rica e do Bode, após irradiação, foram submetidas a tratamento térmico com temperatura da ordem de $300^{\circ} \mathrm{C}$, num período de tempo variando de 5 a 30 minutos (irradiadas a 65kGy) e de 30 a 60 minutos (aquelas irradiadas a $400 \mathrm{kGy}$ ).

Do quartzo de ambientes hidrotermal e pegmatítico, foram criados os matizes de cor representados na Figura 6. O cristal 2 possui $100 \%$ de $\mathrm{SiO}_{2}$. No caso do cristal 3, a cor acastanhada a preta é criada na irradiação e, quando aquecido entre 180 e $360^{\circ} \mathrm{C}$, ele pode retornar a cor inicial (amostra 5 - Mina Comecha) ou aparecer matiz variando de amarelo a acastanhado (amostras 6, 7 e 8 - minas Boca Rica e do Bode), de acordo com aplicação de dose 65 ou 400 kGy. No cristal 4, dependendo da dose em kGy a que é submetido, pode surgir matiz violeta da ametista, já, na irradiação gama,como é o caso daqueles da Mina do Tião (Drummond, 2009).
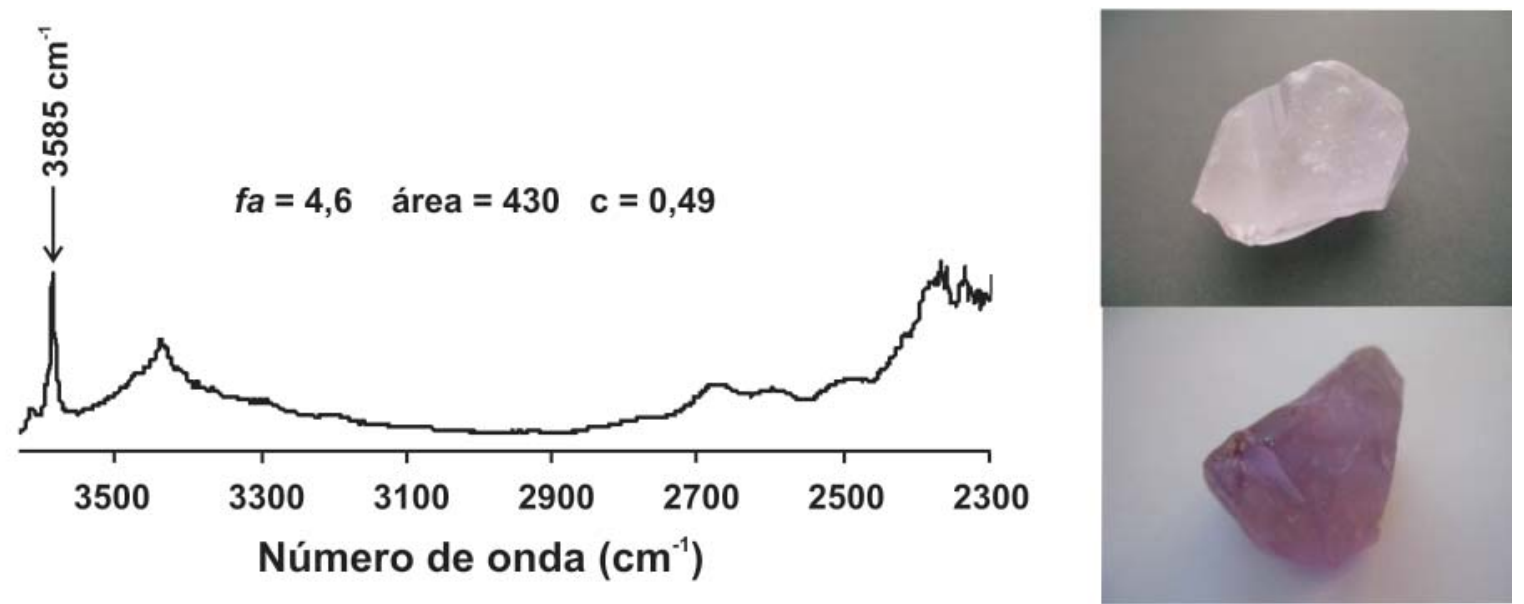

Figura 2 - Espectro de FTIR e fotografias de quartzo hialino natural (com matiz fraco de ametista) e irradiado a 200kGy da Mina do Tião de origem hidrotermal. Desse cristal, pesando 17,2 gramas, pode ser observada a banda $3.585 \mathrm{~cm}^{-1}$ (típico da ametista) e, também, podem ser observados os valores calculados de fa, área e c. 


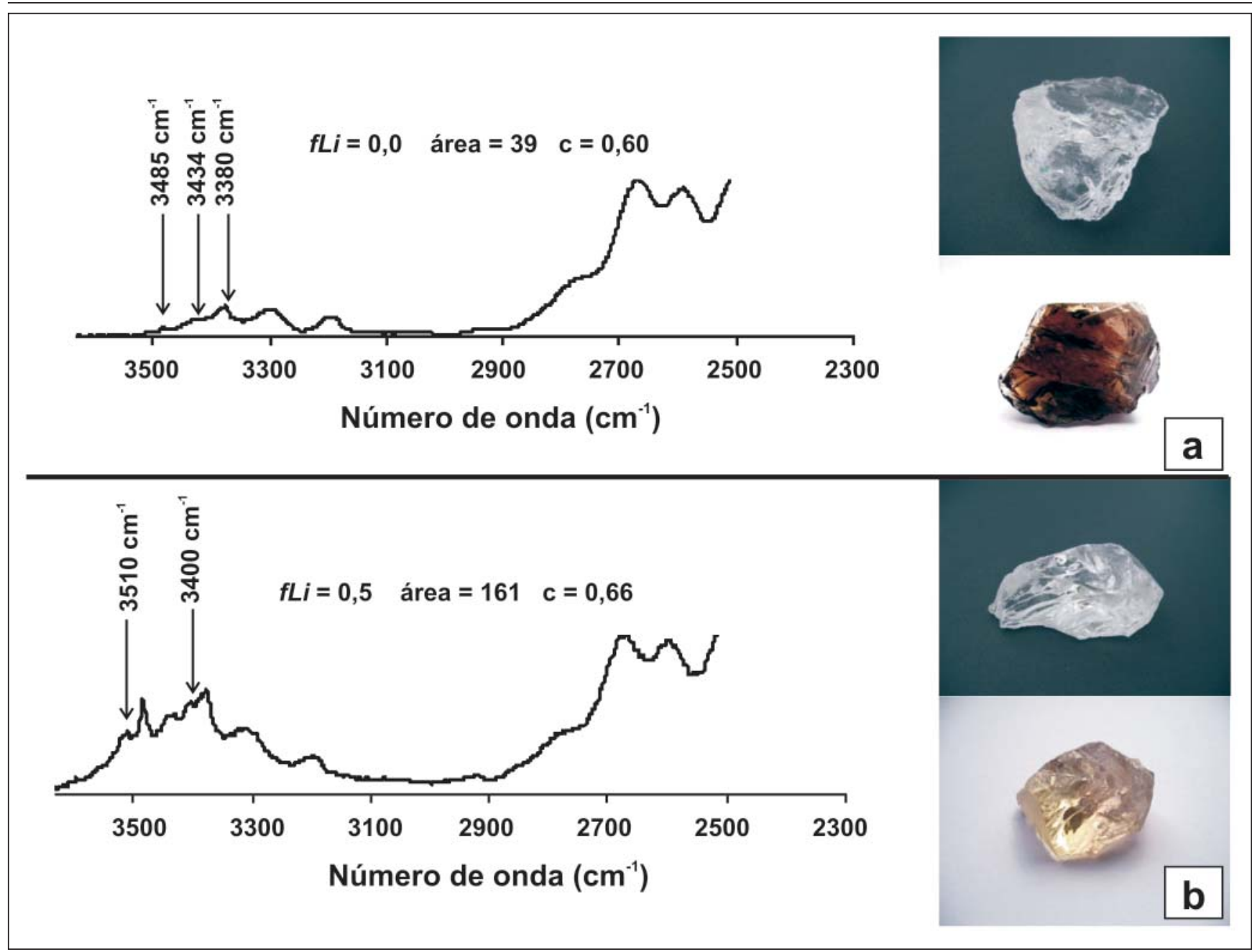

Figura 3 - Espectros de FTIR e fotografias de quartzo hialino natural e irradiado a 300kGy, da Mina Comecha de origem hidrotermal. Desses cristais pesando $a=27,7$ e $b=20,8$ gramas, observam-se as bandas $3.380,3.404,3.434,3.485$ e $3.510 \mathrm{~cm}^{-1}$ (típico do matiz fumê) e os valores calculados de $f L i$, área e c. A amostra "a" foi irradiada e "b", irradiada e aquecida.

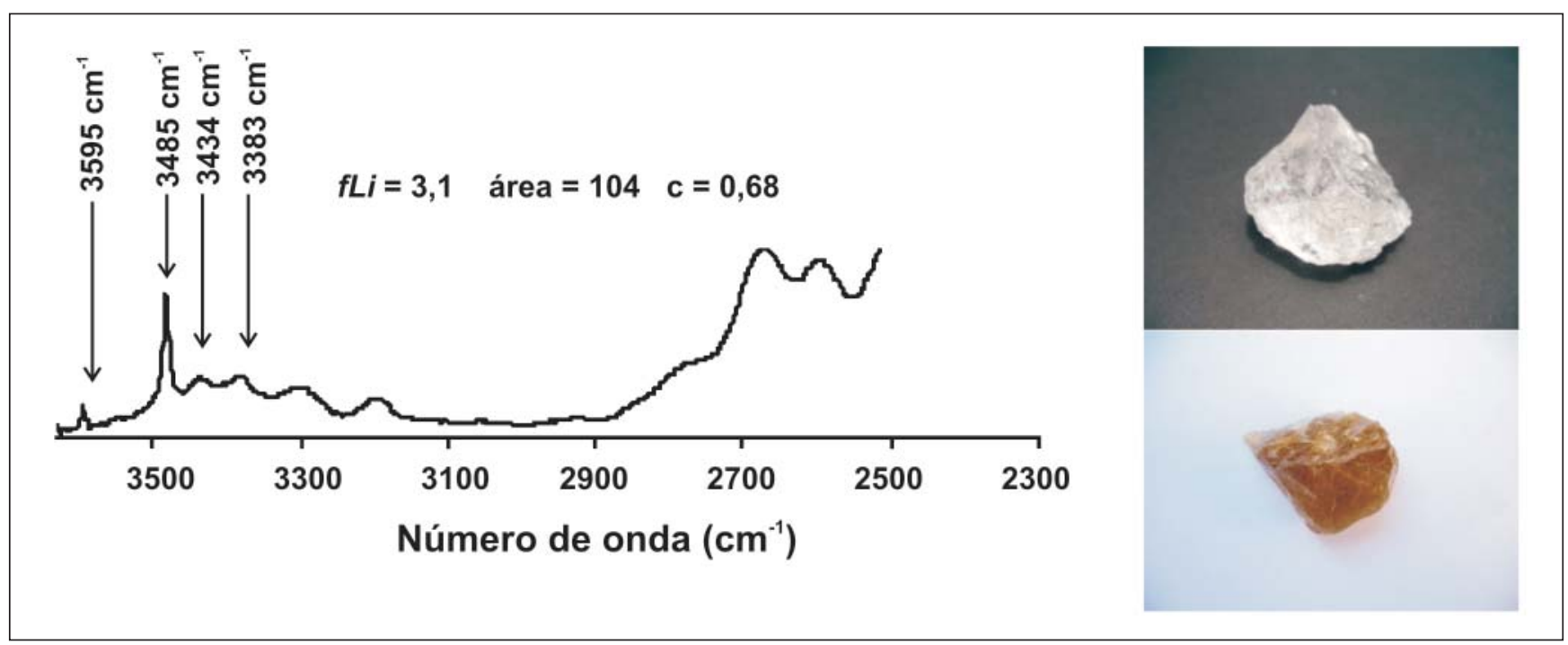

Figura 4 - Espectro de FTIR e fotografias de quartzo hialino natural e irradiado a 400 kGy da Mina Boca Rica de origem pegmatítica. Desse cristal pesando 23,4 gramas, observam-se as bandas de 3.383, 3.434, 3.485 e $3.595 \mathrm{~cm}^{-1}$ (típico do cognac) e os valores calculados de $f L i$, área e c. 


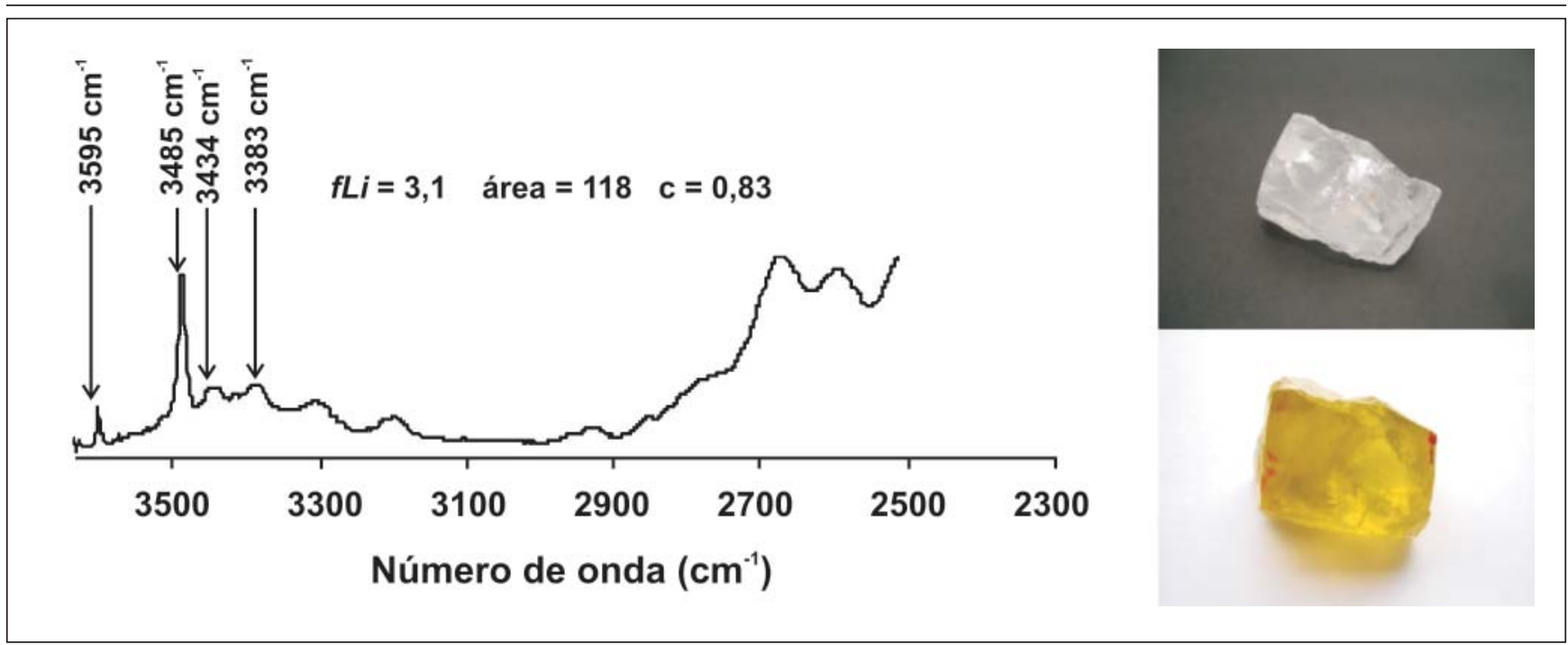

Figura 5 - Espectro de FTIR e fotografias de quartzo hialino natural e irradiado (a 65kGy) e aquecido, da Mina do Bode, de origem pegmatítica. Desse cristal pesando 33,0 gramas, podem ser observados as bandas a 3.383, 3.434, 3.485 e 3.595 $\mathrm{cm}^{-1}$ (típico do green gold), com matiz amarelado, e os valores calculados de $f L i$, área e c.

A Figura 7 exemplifica o resultado dos trabalhos iniciados com a obtenção dos espectros de FTIR e finalizados com irradiação gama e tratamento térmico. Trata-se de um cristal de quartzo bruto de origem pegmatítica da Mina do Bode. O exemplar irradiado e aquecido e a pedra lapidada dele oriunda são exemplos de um produto que pode ser obtido por meio das técnicas que conduzem à criação de cor no quartzo hialino. A cor resultante mostrada na Figura 7 é de um green gold de qualidade muito boa e que tem grande aceitação no mercado mundial de artesanato e de pedras preciosas.

\section{Considerações finais}

As diferentes doses de irradiação aplicadas aos espécimes das minas de origem hidrotermal mostram que a criação de cores é diferenciada nas Minas do Tião e da Comecha. O quartzo hialino do Tião é o único até então conhecido, de onde é possível obter ametista com matiz intenso e muito homogêneo, quando submetido a doses de 200, 400 e 600kGy, sem a necessidade de tratamento térmico. Em quartzo da Mina Comecha, após irradiação, houve o desenvolvimento da coloração acastanhada e em somente uma amostra foi

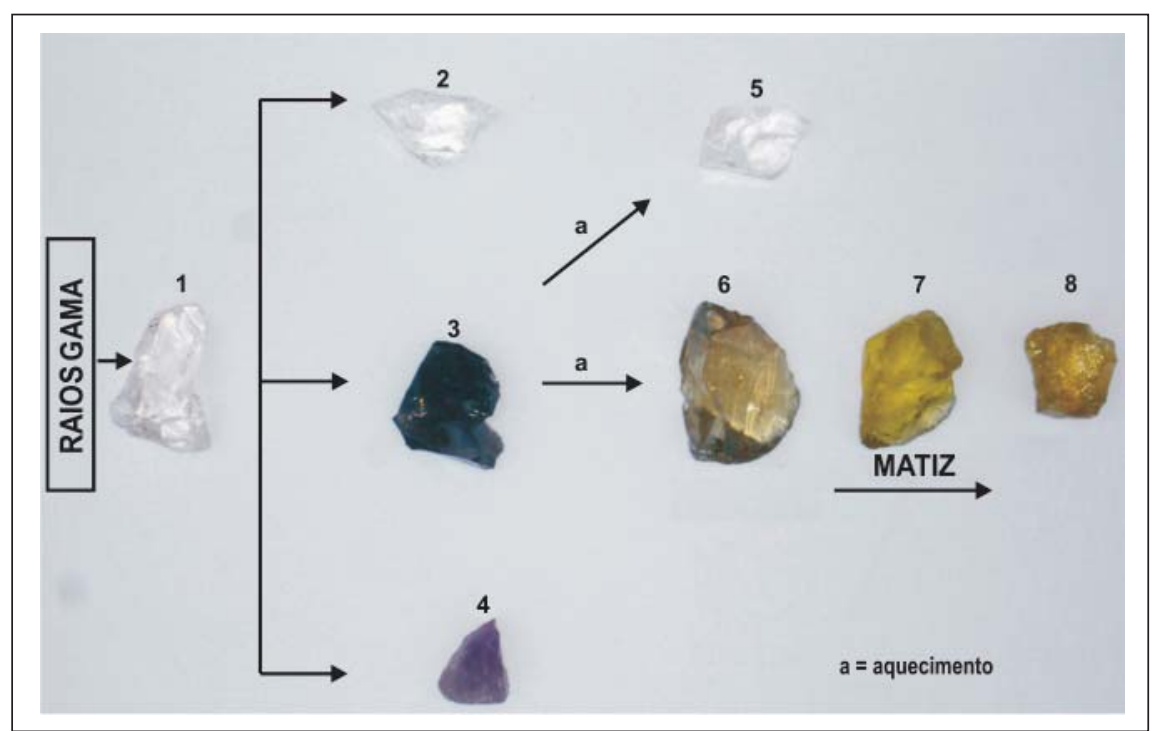

Figura 6 - Resultados da irradiação gama seguida ou não de tratamento térmico de amostras de quartzo hialino de ambiente hidrotermal (Minas do Tião - amostra violeta após a irradiação e Comecha - fumê após a irradiação e matiz incolor após o aquecimento) e pegmatítico (Minas do Bode e Boca Rica - fumê após irradiação e matiz variando de amarelado a acastanhado após o aquecimento). Cada exemplar pesa: $1=18,65,2=15,80,3=17,52,4=11,92,5=15,44$, $6=34,20,7=32,78$, e $8=22,29$ gramas.

observada a cor preta (morion). Algumas amostras, quando submetidas ao tratamento térmico, retornam ao incolor (Drummond, 2009).

Quanto aos resultados de amostras de ambiente pegmatítico, não houve uma grande variação de cor após irradiação gama, sempre seguida de tratamento térmico. Tanto nos espécimes da Mina Boca Rica, quanto na do Bode, quando irradiado a 65kGy e aquecido, foi criado matiz amarelado com um tênue esverdeado, produzindo o green gold, e matiz acastanhado, quando irradiado a 400kGy (Drummond, 2009).

As bandas características de FTIR demonstram que a coloração amarelada, em ambiente pegmatítico, é devida à presença do lítio, que atua como compensador 


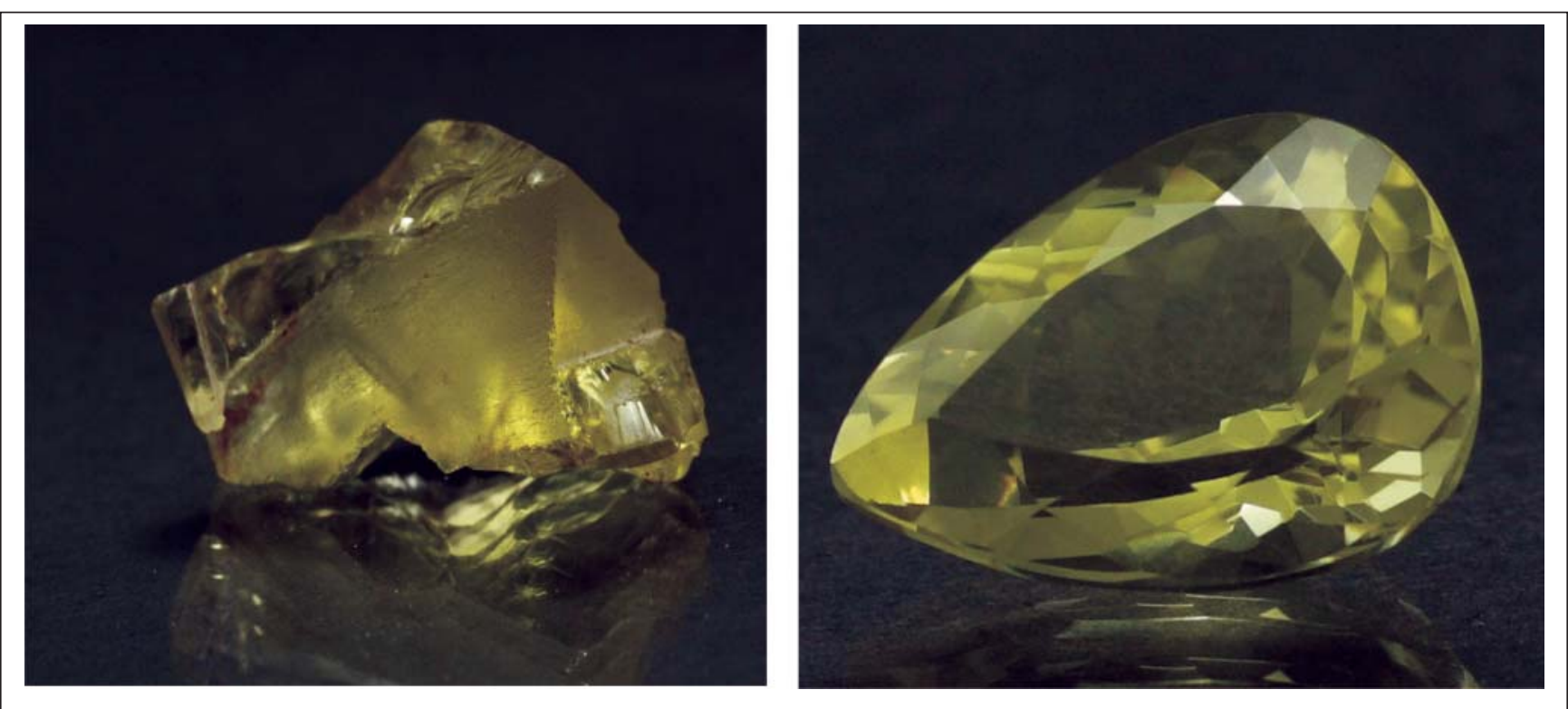

Figura 7 - Fotografias representando um espécime bruto (15,51gramas) da mina pegmatítica do Bode e a pedra lapidada (3,15ct) dele obtida. 0 espécime bruto foi irradiado a $400 \mathrm{kGy}$ e aquecido a $310^{\circ} \mathrm{C}$ por um período de 40 minutos, produzindo um green gold de qualidade excepcional.

do alumínio na estrutura do quartzo. Os resultados apontam para a importância do elemento lítio e sua relação com cores a serem criadas no quartzo de origem pegmatítica. Em pegmatito rico em minerais de lítio, o quartzo apresenta grande potencial para o aparecimento de matizes, tais como green gold, beer, cognac, whisky e champagne.

Finalizando, deve ser ressaltado que análises de FTIR representam indicadores seguros de que o quartzo hialino, de origem hidrotermal e pegmatítica, poderá desenvolver cor depois de submetido à irradiação gama seguida ou não de tratamento térmico. A única ressalva dessa técnica é quanto à definição segura do matiz a ser criado.

\section{Referências bibliográficas}

CAMERON, E.N. et al. Internal structure of granitic pegmatites. Economic Geology, Monograph 2. 1949. 115p.

CARVALHO, A. S. Geologia e gênese das mineralizações de quartzo no Espinhaço Meridional, Minas GeraisBrasil. Brasília: Universidade de Brasília, Departamento de Geociências, 1982. 94 f. (Dissertação de Mestrado).
CASSINI, C.T. A ametista de Pau d Arco e Alto Bonito no Pará e a do Alto Uruguai no Rio Grande do Sul. Belém: Universidade Federal do Pará, Instituto de Geociências, 1998. 84f. (Dissertação de Mestrado).

CHAVES, M. L. S. C., COUTINHO, D. C. Nota sobre a jazida de ametista da Fazenda Sobrado, Felício dos Santos, Minas Gerais. REM- Revista Escola de Minas, v. 45 n.1/2, p.194-199, 1992.

COLLYER, T. A., MÁRTIRES, R. A. C. O depósito de ametista de Alto Bonito, município de Marabá, Pará. In: CONG. BRAS. GEOL., 34. Anais... Goiânia: SBG, 1986. v.5, p.2221-2228.

DRUMMOND, N. F. Ambientes geológicos e mudanças de cor no quartzo hialino. Ouro Preto: Universidade Federal de Ouro Preto, Escola de Minas, Departamento de Geologia, 2009. 195 f. (Dissertação de Mestrado)

FAVACHO-SILVA, M. D. Variedades gemológicas de quartzo em Minas Gerais: geologia, mineralogia, causas de cor, técnicas de tratamento e aspectos mercadológicos. Belo Horizonte: Universidade Federal de Minas Gerais, Instituto de Geociências, 2000. 155 f. (Dissertação de Mestrado).

FAVACHO-SILVA, M. D. et al. Tratamento em gemas. In: Gemas de Minas Gerais. Belo Horizonte: SBG-MG, 2001. 279p. cap. 3, p. 52-73.

JOHNSTON JR, W. D. Os pegmatitos berilo-tantalíferos da Paraíba e Rio Grande do Norte, no nordeste do Brasil. Boletim DNPM/DFPM, Rio de Janeiro, n. 72, 83p. 1945 a.

. Pegmatitos ambligonita-berilo-tantaliferos do Ceará, nordeste do Brasil. Boletim DNPM/DFPM, Rio de Janeiro, avulso 66, 1945 b. 44p.

LAMEIRAS, F. S. Relatório interno do Centro de Desenvolvimento da Tecnologia Nuclear. Belo Horizonte, MG: CDTN, 2007. (Documento inédito).

LAMEIRAS, F. S. et al. Identificação de quartzos incolores para joalheria. REM - Revista Escola de Minas, v.59, n.1, p.129-133, 2006.

MORAES, L. J. de. Geologia geral. Boletim DNPM/SFPM, Rio de Janeiro, n. 19, parte I, p. 7-111, 1937.

NASSAU, K. Gemstone enhancement: history, science and state of the art. Oxford: Butterworth-Heinemann, 1994. 252p.

NUNES, E. H. M. Caracterização das ametistas naturais. Belo Horizonte: Universidade Federal de Minas Gerais, Escola de Engenharia, 2008. 197 f. (Tese de Doutorado).

NUNES, E. H. M. et al. Determination of the potencial for extrinsic color development in natural colorless quartz. American Mineralogist, v.94, p 935-941. 2009.

PAIVA, G. de. Províncias pegmatíticas do Brasil. Boletim DNPM/DFPM, Rio de Janeiro, n. 78, p. 13-22, 1946.

Artigo recebido em 21/09/2009 e aprovado em 27/05/2010. 